\title{
Case Report: Management of idiopathic chylothorax [version
}

\section{1; peer review: 1 approved, 1 not approved]}

\section{Maher Abouda (D1, Yangui Ferdaous¹, Miriam Triki¹, Mehdi Charfi², Mohamed Ridha Charfi ${ }^{1}$}

${ }^{1}$ Respiratory Department, FSI Hospital, La Marsa, Tunisia

${ }^{2}$ Radiology Department, FSI Hospital, La Marsa, Tunisia

V1 First published: 12 Oct 2015, 4:1049

https://doi.org/10.12688/f1000research.6694.1

Latest published: 12 Oct 2015, 4:1049

https://doi.org/10.12688/f1000research.6694.1

\section{Abstract}

Chylothorax is characterized by the presence of chyle in the pleural space and results from lesion or obstruction of the thoracic duct. We present two cases of non-traumatic, idiopathic chylothorax in two females that were treated differently. The first is a 42 year old female who presented with a symptomatic right chylothorax. Treatment by a low-fat diet supplemented with medium chain triglyceride and evacuation of the pleural fluid was sufficient. The second patient is a 25 year old female admitted for a bilateral chylothorax. Despite optimal medical therapy, chylothorax continued to persist. Finally thoracic duct ligation was performed, which resulted in resolution of the effusion. These two cases illustrate that the management of idiopathic chylothorax can be surgical or nonsurgical.

\section{Keywords}

Pleural diseases, Idiopathic chylothorax, thoracic duct, chyle , surgery, diet

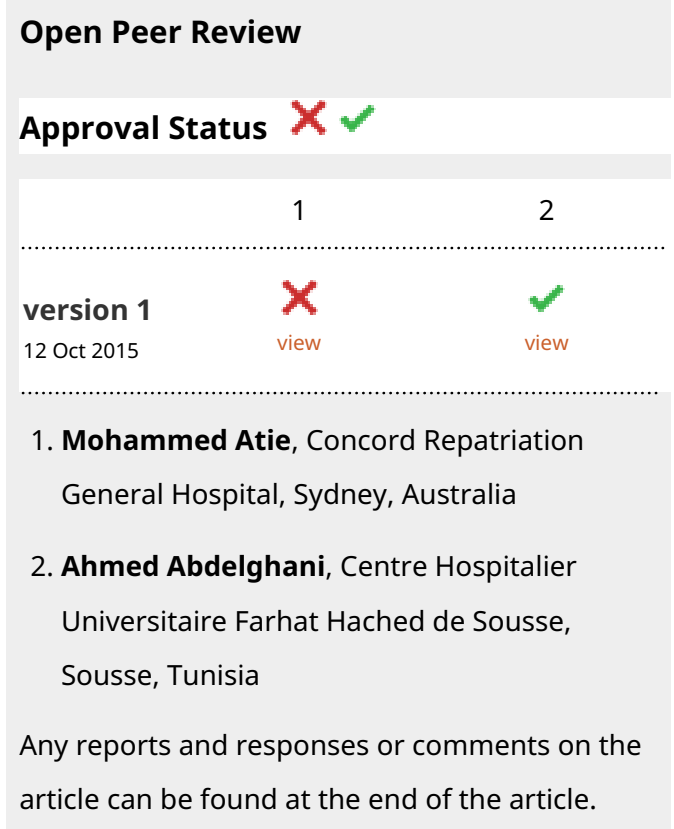

Corresponding author: Maher Abouda (maherabouda@yahoo.fr)

Competing interests: No competing interests were disclosed.

Grant information: The authors declared that no grants were involved in supporting this work.

Copyright: (c) 2015 Abouda $\mathrm{M}$ et al. This is an open access article distributed under the terms of the Creative Commons Attribution License, which permits unrestricted use, distribution, and reproduction in any medium, provided the original work is properly cited.

How to cite this article: Abouda M, Ferdaous Y, Triki M et al. Case Report: Management of idiopathic chylothorax [version 1; peer review: 1 approved, 1 not approved] F1000Research 2015, 4:1049 https://doi.org/10.12688/f1000research.6694.1

First published: 12 Oct 2015, 4:1049 https://doi.org/10.12688/f1000research.6694.1 


\section{Introduction}

Chylothorax is characterized by the presence of chyle, which is rich in triglycerides and chylomicrons in the pleural space resulting from damage of the thoracic duct ${ }^{1,2}$. In the etiology of chylothorax, traumas and malignancies are the first two leading causes ${ }^{2}$. Idiopathic chylothorax in adults is a rare clinical condition that can be retained only after ruling out all other causes of chylothorax ${ }^{3}$. The management of idiopathic chylothorax can be surgical or nonsurgical ${ }^{4}$. We report two cases of spontaneous chylothorax in adults, that were treated differently.

\section{Case report 1}

A previously healthy, 42 year old woman who was a non-smoker, presented with two days history of right chest pain. She was first evaluated in the consultation. At the chest physical examination, dullness to percussion with decreased breath sound over the right lung base was noted. There was no history of trauma, recent infection, fever or weight loss. Posteroanterior (Figure 1) and lateral chest radiographs demonstrated right pleural fluid collection. Routine laboratory studies (including complete blood count, erythrocyte sedimentation rate, coagulation, liver and renal function tests, and lipid profile) were within normal limits. Thoracentesis yielded a creamy-milky like fluid (Figure 2), with protein levels $86 \mathrm{~g} / \mathrm{l}$, triglycerides $2253 \mathrm{mg} / \mathrm{dl}$, cholesterol $124 \mathrm{mg} / \mathrm{dl}$ and white blood cell count $78 / \mathrm{mm}^{3}$ (30 percent polymorphonuclear leukocytes and 70 percent lymphocytes) confirming the laboratory testing profile of chylothorax. A bronchoscopy was performed and shows a normal bronchial tree. The bacteriologic and cytologic analyses of the endobronchial aspiration fluid were normal. Complementary laboratory studies such as antinuclear antibody and viral serology, were negative. A computed tomography (CT) scan of the chest and abdomen was normal and shows no evidence of tumor or lymphadenopathies. Treatment consisted of relative rest and a medium-chain triglyceride diet and evacuation of the pleural fluid by multiple thoracentesis. In few days, the effusion had completely resolved, and at one year, the patient remained asymptomatic.

\section{Case report 2}

A 25 year old woman, non-smoker, was admitted for a bilateral pleural effusion fortuity discovered by a chest radiography (Figure 3). The effusion was predominant in the right side. There was no history of trauma, recent pulmonary infection, or weight loss. Routine laboratory studies (including complete blood count, erythrocyte sedimentation rate, coagulation, liver and renal function tests, and lipid profile) were within normal limits. Right thoracentesis yielded a red-milky like fluid, with protein levels $56 \mathrm{~g} / \mathrm{l}$, triglycerides $3200 \mathrm{mg} / \mathrm{dl}$, cholesterol $140 \mathrm{mg} / \mathrm{dl}$, white blood cell count 165/ $\mathrm{mm}^{3}$ (22 percent polymorphonuclear leukocytes and 78 percent lymphocytes) and numerous red blood cells confirming the laboratory testing profile of chylothorax. All explorations such as bronchoscopy, bacteriologic and cytologic analyses, antinuclear antibody and viral serology were negative. A CT scan of the chest and abdomen was normal and shows no evidence of tumor or lymphadenopathies. At first a non-surgical therapy was tried, including a modified diet, chest tube insertion and total parenteral nutrition. Yet, despite optimal medical therapy, the effusion worsened with appearance of ascites. A second CT scan of the chest shows the accentuation of the effusion, particularly in the left side (Figure 4).

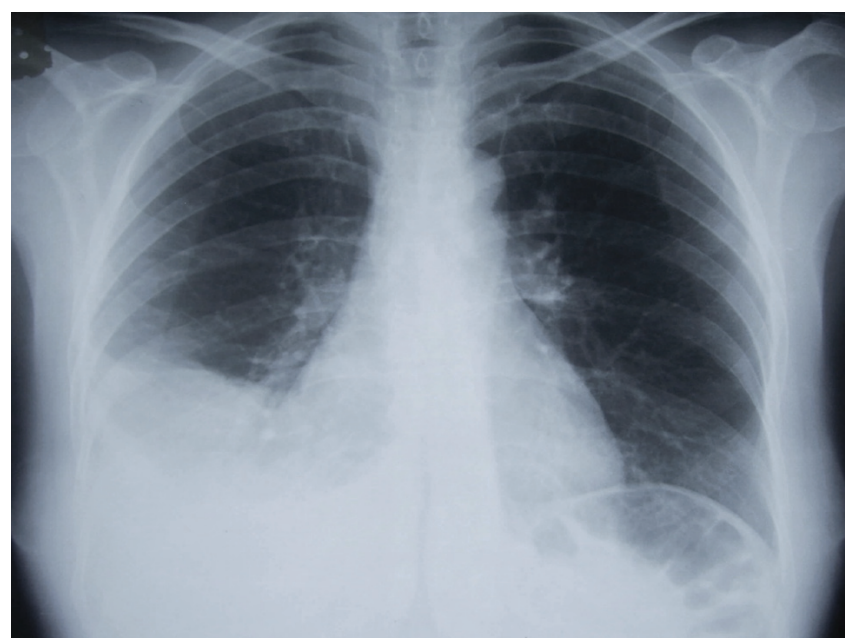

Figure 1. Chest radiograph showing right pleural fluid collection.

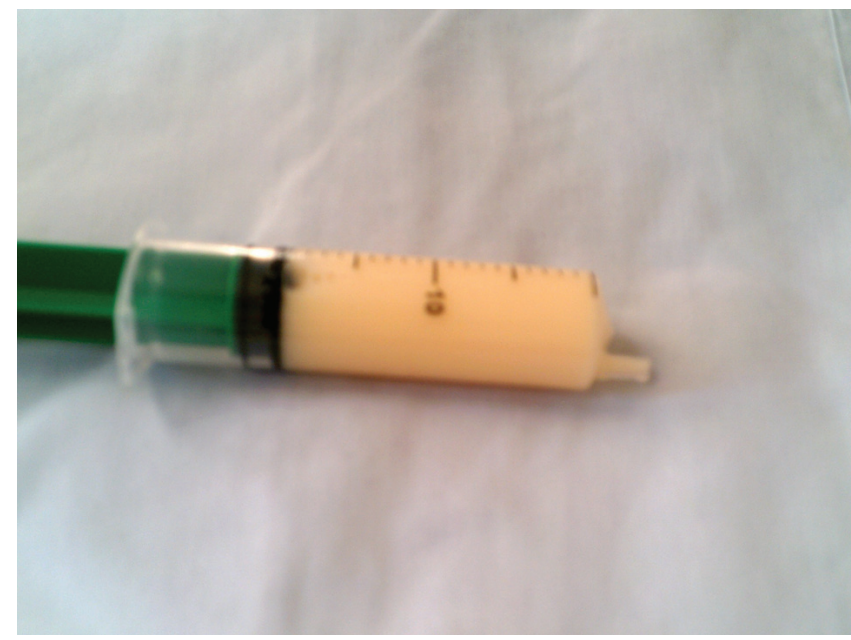

Figure 2. Milky pleural fluid.

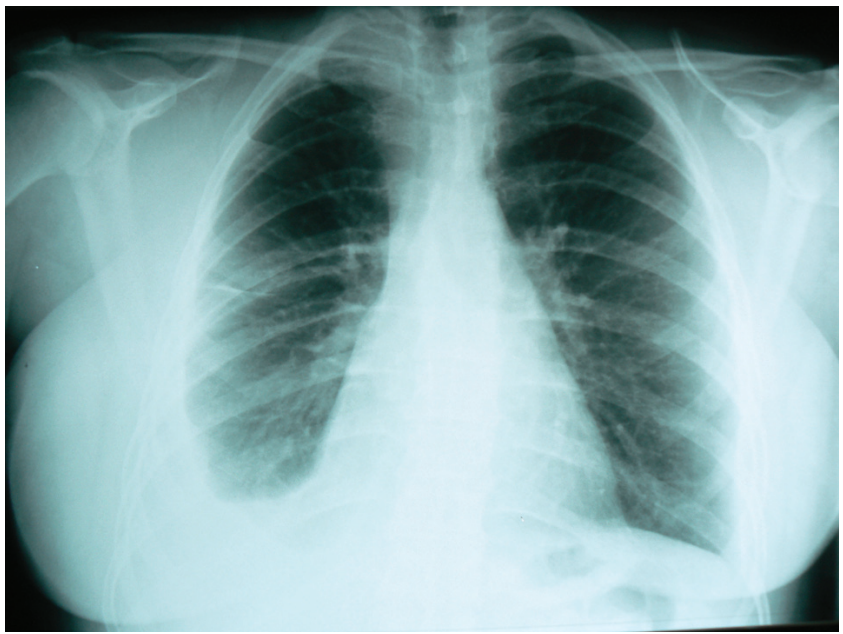

Figure 3. Chest radiograph showing a bilateral pleural effusion. 


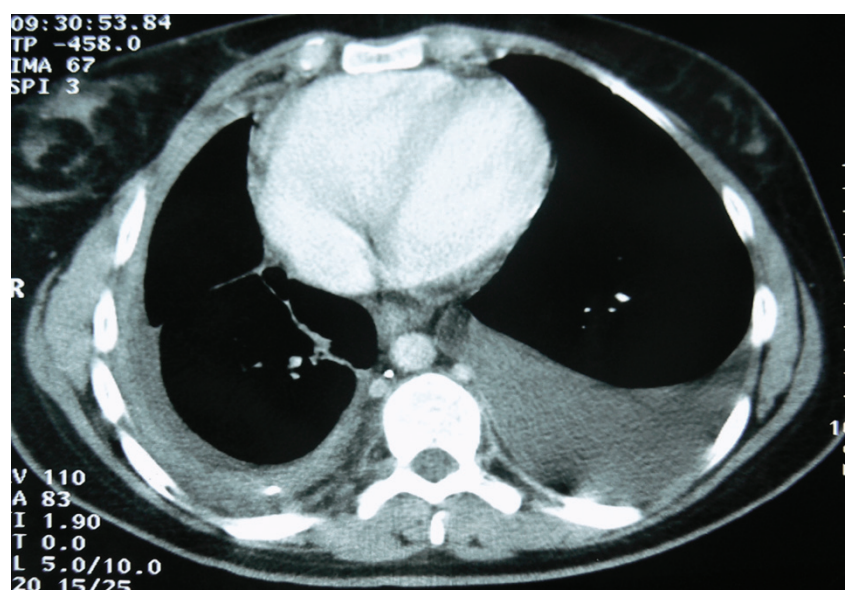

Figure 4. CT scan showing a bilateral effusion.

Surgical thoracic duct ligation at the level of the seventh dorsal vertebra was performed. The resolution of the effusion was obtained after two weeks. At two years, the patient remained asymptomatic.

\section{Discussion}

Chylothorax is a relatively uncommon cause of pleural fluid collection, causing 3 percent of pleural effusions ${ }^{2}$. The pleural fluid in chylothorax is rich in triglycerides and chylomicrons. This fluid is the chyle from the intestine, liver and abdominal wall, that flows in the pleural space after a rupture, laceration or obstruction of the thoracic duct ${ }^{5}$. Damage of the thoracic duct can occur after thoracic trauma or thoracic surgery (49 percent), or in various other medical conditions (43 percent) such as: central venous catheterization, extensive venous thrombosis in the neck, compression by mediastinal lymphadenopathy such as in non-Hodgkin's lymphoma ${ }^{2,6}$. In about 6.4 percent of cases no reason can be found for the chylous pleural effusion ${ }^{2}$. Most of these idiopathic chylothoraces are thought to be related to minor trauma. In our cases, no trauma was reported by the patient. Chylothorax presents as a non-infectious pleural effusion causing non-specific symptoms such as cough, asthenia or abdominal pain, and sometimes respiratory distress ${ }^{1-6}$. Chylothorax is easily diagnosed by thoracocentisis. Biochemical and other analyses of the pleural fluid are the most important diagnostic step. The pleural fluid appearance is generally milkly white or whitish. Pleural fluid triglyceride levels have been used in diagnosing chylothorax. Level of pleural fluid triglyceride must be $>1.10 \mathrm{mg} / \mathrm{dl}$. Presence of chylomicrons, low cholesterol level, and elevated percentage of lymphocyte are necessary for the diagnosis of chylothorax ${ }^{1,6}$. In non-traumatic or non-chirurgical cases, CT abdomen and thorax scans should be performed to rule out association with malignancy or tuberculosis ${ }^{2,3}$. This may demonstrate evidence of tumor or lymphadenopathy. Lymphangiography may be used to demonstrate the side of leakage or blockage ${ }^{6}$. In our hospital lymphography is not performed. In countries with relatively high incidence of tuberculosis, like in North Africa, sputum acid fast bacillus smear and culture may be helpful in etiologic diagnosis. In some cases laboratory studies such as antinuclear antibody and viral serology must be performed, especially in women ${ }^{7}$. Treatment is controversial and can be either conservative or surgical. Conservative treatment includes the use of a low-fat diet supplemented with medium chain triglycerides (MCT) and/or total parenteral nutrition $(\mathrm{TPN})^{4}$. In our first case, a low-fat diet without long chain triglycerides was maintained to limit lymph flow with good evolution and regression of the chylothorax. Octreotide, a somatostatin analogue, may be used for the management of patients with refractory chylothorax $^{8}$. The use of intrapleural streptokinase is not established but can be proposed for patients with idiopathic chylothorax who failed conservative therapy but refused surgery ${ }^{10}$. Drainage of the effusion by thoracocentesis or chest tube insertion is necessary in cases of significant respiratory distress or important effusion ${ }^{4,6}$. In case of therapeutic failure, surgery is required. Surgery may act on the leak itself: ligation of the thoracic duct, sutures of the leaking collaterals, or various other procedures ${ }^{4,6,11}$. Invasive chirurgical treatment with low efficacy such as pleuroperitoneal shunt or pleurodesis is indicated in recurrent chylothorax or in extensive lesion ${ }^{12}$.

\section{Conclusion}

The pleural fluid in chylothorax is the chyle from the intestines, liver and abdominal wall that flows in the pleural space after a rupture, laceration or obstruction of the thoracic duct and diagnosis is easily made by Thoracentesis. In about 6.4 percent of chylothoax no reason can be found for the pleural effusion. In such cases Treatment is controversial and can be either conservative or surgical.

\section{Consent}

Written informed consent for publication of clinical details and images was obtained from the patients.

\section{Author contributions}

$\mathrm{AM}, \mathrm{YF}$ and TM carried out the cases. CM contributed to the selection of images. AM and YF contributed to preparation of the manuscript. All authors were involved in the revision of the draft manuscript and have agreed to the final content.

\section{Competing interests}

No competing interests were disclosed.

\section{Grant information}

The author(s) declared that no grants were involved in supporting this work. 
1. Hillerdal G: Chylothorax and pseudochylothorax. Eur Respir J. 1997; 10(5): 1157-62.

PubMed Abstract | Publisher Full Text

2. Doerr $\mathrm{CH}$, Allen MS, Nichols FC 3rd, et al:: Etiology of chylothorax in 203 patients. Mayo Clin Proc. 2005; 80(7): 867-870.

PubMed Abstract | Publisher Full Text

3. Romero S: Nontraumatic chylothorax. Curr Opin Pulm Med. 2000; 6(4): 287-91. PubMed Abstract | Publisher Full Text

4. Epaud R, Dubern B, Larroquet $\mathrm{M}$, et al:: Therapeutic strategies for idiopathic chylothorax. J Pediatr Surg. 2008; 43(3): 461-465.

PubMed Abstract | Publisher Full Text

5. Steinemann DC, Dindo D, Clavien PA, et al:: Atraumatic chylous ascites: systematic review on symptoms and causes. J Am Coll Surg. 2011; 212(5): 899-905.e1-4. PubMed Abstract | Publisher Full Text

6. Büttiker V, Fanconi S, Burger R: Chylothorax in children: guidelines for diagnosis and management. Chest. 1999; 116(3): 682-7. PubMed Abstract | Publisher Full Text

7. Manzella DJ, Dettori PN, Hertimian ML, et al.: Chylous ascites and chylothorax as presentation of a systemic progression of discoid lupus. J Clin Rheumatol.
2013; 19(2): 87-89.

PubMed Abstract | Publisher Full Text

8. Hashim SA, Roholt HB, Babayan VK, et al:: Treatment of chyluria and chylothorax with medium-chain triglyceride. N Engl J Med. 1964; 270: 756-761.

PubMed Abstract | Publisher Full Text

9. Roehr CC, Jung A, Proquitté $\mathrm{H}$, et al.: Somatostatin or octreotide as treatment options for chylothorax in young children: a systematic review. Intensive Care Med. 2006; 32(5): 650-657.

PubMed Abstract | Publisher Full Text

10. Kuan YC, How SH, Ng TH, et al.: Intrapleural streptokinase for the treatment of chylothorax. Respir Care. 2011; 56(12): 1953-1955.

PubMed Abstract | Publisher Full Text

11. Cevese PG, Vecchioni R, D'Amico DF, et al.: Postoperative chylothorax. Six cases in $\mathbf{2 , 5 0 0}$ operations, with a survey of the world literature. J Thorac Cardiovasc Surg. 1975; 69(6): 966-971.

PubMed Abstract

12. Murphy MC, Newman BM, Rodgers BM: Pleuroperitoneal shunts in the management of persistent chylothorax. Ann Thorac Surg. 1989; 48(2): 195-200.

PubMed Abstract | Publisher Full Text 


\title{
Open Peer Review
}

\section{Current Peer Review Status:}

\section{Version 1}

Reviewer Report 11 July 2016

https://doi.org/10.5256/f1000research.7190.r14897

(C) 2016 Abdelghani A. This is an open access peer review report distributed under the terms of the Creative Commons Attribution License, which permits unrestricted use, distribution, and reproduction in any medium, provided the original work is properly cited.

\begin{abstract}
Ahmed Abdelghani
Service de pneumologie, Centre Hospitalier Universitaire Farhat Hached de Sousse, Sousse, Tunisia

The authors report tow cases of pleural effusion as an initial presentation of the thoracic duct lesion. While the diagnosis of chylothorax is easy, the idiopathic origin of the affection can be retained only after ruling out all other causes of chylothorax. The chylothorax seem to be idiopathic in the two cases, however the authors do not explain how idiopathic chylothorax can be located at left side.

This article points out the difficulty of the treatment which can be either conservative or surgical.

Competing Interests: No competing interests were disclosed.

I confirm that I have read this submission and believe that I have an appropriate level of expertise to confirm that it is of an acceptable scientific standard.
\end{abstract}

Reviewer Report 24 June 2016

https://doi.org/10.5256/f1000research.7190.r14560

(C) 2016 Atie M. This is an open access peer review report distributed under the terms of the Creative Commons Attribution License, which permits unrestricted use, distribution, and reproduction in any medium, provided the original work is properly cited.

\section{Mohammed Atie}

Department of Upper GI Surgery, Concord Repatriation General Hospital, Sydney, NSW, Australia

It is crucial when a chylothorax is being either medically or surgically treated to state the volumes of chyle that are produced on a daily basis. This dictates further management. The authors fail to 
provide that.

The thoracic duct passes from the cysterna chyli directly into the right pleural space. Anatomically, there is no communication between the right pleural space and the left pleural space. While a left sided chylothorax is possible after surgical intervention due to disruption of the left pleura, idiopathic chylothrorax is normally right sided. The authors fail to provide an explanation of how chyle from the thoracic duct's main trunk tracked into the left chest.

Supposing that the leak into the left chest was from an aberrant or side branch that originated at point below the right pleural space, how did the authors identify that? Locating the thoracic duct main trunk is feasible surgically, but locating a side branch proves impossible surgically even with prior localisation by means of lymphangiography. I presume that the thoracic duct ligation was done blindly at the level of the hiatus.

The authors highlight two methods for the management of chylothorax. These methods have been well established and the report itself does not add any new material to what is already known from the literature.

Competing Interests: No competing interests were disclosed.

I confirm that I have read this submission and believe that I have an appropriate level of expertise to state that I do not consider it to be of an acceptable scientific standard, for reasons outlined above.

The benefits of publishing with F1000Research:

- Your article is published within days, with no editorial bias

- You can publish traditional articles, null/negative results, case reports, data notes and more

- The peer review process is transparent and collaborative

- Your article is indexed in PubMed after passing peer review

- Dedicated customer support at every stage

For pre-submission enquiries, contact research@f1000.com 